\title{
ELOY SÁNCHEZ ROSILLO A LA LUZ DE LEOPARDI: UNA VIEJA COSTUMBRE, UN CAMINO DISTINTO
}

\author{
ELOY SÁNCHEZ ROSILLO IN THE \\ LIGHT OF LEOPARDI: AN OLD \\ HABIT, A DIFFERENT PATH
}

\author{
Pablo NúÑEZ DíaZ \\ Universidad de Valladolid
}

Resumen: Eloy Sánchez Rosillo encontró en Giacomo Leopardi un referente esencial para su formación poética, desde que lo leyó con detenimiento en el verano que pasó en Italia en 1973. De hecho, Sánchez Rosillo publicó en 1998 su personal antología de los Cantos, con introducción, traducción y notas propias, que resulta ciertamente valiosa para comprender la relación que se establece entre las obras de ambos escritores. El objetivo de este trabajo es profundizar en 1) las características comunes (la claridad, el contenido elegíaco, la desesperanza, el amor, la presencia de la naturaleza y de elementos como la luna),2) la lectura que Sánchez Rosillo hace del desengaño vital de los Cantos y 3) el modo en que asume parte sustancial del magisterio de Leopardi, pero aporta, al mismo tiempo, un camino nuevo.

Palabras clave: Eloy Sánchez Rosillo; Giacomo Leopardi; Cantos; claridad; tempus fugit.

AbSTRACT: Eloy Sánchez Rosillo found in Giacomo Leopardi an essential reference for his poetic training since he read it thoroughly in the summer he spent in Italy in 1973. In fact, Sánchez Rosillo published his anthology of the Cantos in 1998, with his own introduction, translation and notes, which is certainly valuable for understanding the relationship established between the works of both writers. The aim of this work is to deepen into 1) the common characteristics (clarity, elegiac content, hopelessness, love, the presence of nature and elements such as the moon), 2) Sánchez Rosillo's reading of vital disappointment in the Cantos and 3) the way in which he assumes a substantial part of Leopardi's teaching, but contributes, at the same time, with a new path.

KeY wORDs: Eloy Sánchez Rosillo; Giacomo Leopardi; Cantos; clarity; tempus fugit. 
Los Cantos (1831) de Giacomo Leopardi resultaron fundamentales en la formación poética de Eloy Sánchez Rosillo (Murcia, 1948) desde que los leyó en profundidad durante un verano en Italia en 1973, que pasó estudiando italiano en la Università per Stranieri di Perugia y viajando por toda la península (Sánchez Rosillo, 2004a: 9-10). El autor español señala que la poesía de los Cantos, «tan emocionada, tan directa, tan cristalina», se convirtió para él en «una especie de antídoto contra la poesía ininteligible, intelectualoide y fría que muchos de los poetas más tempranos de mi generación estaban haciendo por entonces», en referencia a la primera nómina de poetas de la generación de 1968 o novísimos, que se caracterizaba por el hermetismo y por un culturalismo extremo (sobre dicha generación, vid. Prieto de Paula, 1996; Lanz, 2011; Iravedra, 2016: 61-68). La poesía de Leopardi fue tan importante en su desarrollo como escritor que, según indica, "en momentos de desaliento, me animaba a seguir el camino distinto que yo había empezado a recorrer» (Sánchez Rosillo, 2004a: 10).

En sus más de cuarenta años de trayectoria poética, Sánchez Rosillo ha sido fiel a esa idea de emoción sincera y de claridad, pero, en aspectos como el modo de enfrentarse al paso del tiempo, su planteamiento se ha visto cuando menos matizado, en consonancia con su maduración vital y literaria. En este sentido, el propio Sánchez Rosillo (2018: 10) apunta a su libro La certeza (2005, Premio Nacional de la Crítica) como la obra de transición que marca el cambio de una poesía mayoritariamente elegíaca — de Maneras de estar solo (1978) a La vida (1996) - a otra en que lo celebrativo termina imponiéndose — de Oír la luz (2008) a Quién lo diría (2015), y en la misma línea ha de leerse el libro publicado posteriormente, La rama verde (2020, Premio Nacional de Literatura)-

Sánchez Rosillo (1999: 8-9) ha reconocido ser «un admirador muy antiguo, muy fiel y muy ferviente» de Leopardi. Sin embargo, a pesar de que el poeta de Recanati llegó a convertirse para él en «una vieja costumbre» (Sánchez Rosillo, 2004a: 9), supo desarrollar una poética propia. En este artículo se abordará la importancia que el magisterio de los Cantos leopardianos ha tenido en su obra y cómo evoluciona ese vínculo conforme cambia su modo de entender el paso del tiempo.

Como fuentes principales tomaré la obra completa del poeta que nos ocupa, Las cosas como fueron, en su edición de 2018, y el 
mencionado La rama verde (2020); la Antología poética (Leopardi, 2004 [1998]) que Sánchez Rosillo editó y tradujo con poemas de los Cantos $^{1}$, con una introducción y unas notas muy esclarecedoras, así como escritos y entrevistas en los que reflexiona sobre Leopardi. En lo que se refiere al autor italiano, manejaré también las ediciones de los Cantos de Sergio Solmi (1956) y de Andrea Campana (2014), así como las traducciones de Diego Navarro (1994) y Antonio Colinas $^{2}$ (2006).

\section{ALGUNOS ECOS LEOPARDIANOS}

Sánchez Rosillo (1999: 8-9) afirma que le gusta pensar que algo habrá aprendido de Leopardi, «de la precisión y de la transparencia de su palabra concisa, de su manera de entender el tiempo, de su emocionada meditación elegíaca sobre las cosas del mundo». También señala que Leopardi «me reveló el tono adecuado para la expresión de la intimidad verdadera» (en López-Vega, 2016: 49). Estos elementos han sido sustanciales a su poética. Así, la claridad y la naturalidad de la poesía del escritor español, en la que se sustenta, en buena medida, su personal voz, ha sido bien señalada por distintos estudiosos: por ejemplo, García Martín (1992: 88, 95) ha hablado

1 Jaime Siles (2001: 86) defiende que esta obra es «una traducción hecha con voluntad, rigor y estética de orfebre [...]; que ofrece la mejor versión de "Il passero solitario" que conozco; que conserva la cohesión e intensidad de "L'Infinito"; que mantiene la relación entre ritmo y sintaxis; que resuelve con acierto la dificil interpunción leopardiana; que, como en el verso último del "Canto Notturno di un pastore errante dell'Asia", no solo transfiere sino que lo mejora; que no "recrea" sino que reproduce; que es fiel al orden de palabras y a la unidad de frase; y que ofrece una imagen de Leopardi, que supone un adentrarse por sus galerías y un navegar por su interioridad».

2 Para Antonio Colinas y para Andrés Trapiello, poetas de la misma generación que Sánchez Rosillo, Leopardi también ha sido una referencia fundamental (Ladrón de Guevara, 2000; 2005). La nómina de escritores españoles de períodos anteriores que ya habían dejado constancia de su interés por Leopardi, mediante estudios y traducciones de poemas o mediante la presencia del italiano en sus propias obras, es muy relevante. Puede mencionarse, por ejemplo, a Juan Valera, Ramón de Campoamor, Miguel de Unamuno, Juan Ramón Jiménez, Jorge Guillén o Luis Cernuda, entre otros. Para una panorámica al respecto, centrada en la poesía, vid. Ladrón de Guevara (2000; 2005), que menciona las traducciones de Sánchez Rosillo de los Cantos y su poema «Recanati, agosto de 1829 (Homenaje a Giacomo Leopardi)», en el que nos detendremos más adelante (Ladrón de Guevara, 2005: 49-50). 
de «la emoción, la sobriedad y la intensidad de sus versos» y lo ha situado "en las antípodas del poeta hermético»; Díez de Revenga (1992: 191) se refiere al «personalísimo sentido de la claridad como forma de expresión poética», mientras que García de la Concha (1993: 8) ha destacado que Sánchez Rosillo logra «la voz medida» soñada por Antonio Machado:

una voz y tono de conversación consigo mismo, que nada tiene que ver, por su rica, aunque contenida musicalidad, con las voces desvitalizadas de quienes se refugian en el tono menor porque el aliento no les da para más.

El propio Sánchez Rosillo se ha referido a su objetivo de escribir una poesía "transparente o cristalina» (en Eire, 2005: 160). Esta voluntad atraviesa toda la obra del escritor con idéntica relevancia, y puede, ciertamente, relacionarse con las cualidades que a Sánchez Rosillo (2004a: 177) le atraen de Leopardi. En concreto, de lo que denomina primera época de la poesía de Leopardi, que para él es «la mejor, sin duda, por la límpida concisión, el equilibrio y la plasticidad de su lenguaje, y por la naturalidad del mundo que las composiciones nos revelan». En cambio, la que considera segunda y última etapa le resulta «más abstracta, filosófica y discursiva, a pesar de sus altos logros ocasionales». Para Sánchez Rosillo (2004a: 177), el poema de transición entre ambas etapas sería «Canto nocturno de un pastor errante de Asia", compuesto entre el 22 de octubre de 1829 y el 9 de abril de 1830 (las fechas coinciden con las que indica Andrea Campana, 2014: 41). El poema sería posterior a «La calma después de la tormenta» y a "El sábado en la aldea», como señala Sánchez Rosillo (2004a: 176), que pertenecerían, por tanto, a dicha primera etapa.

De ahí que resulte de tanto interés recurrir a la edición que el autor llevó a cabo con diecinueve de los cuarenta y un Cantos $^{3}$, porque

3 Se trata de «Il passero solitario», «L'infinito», «La sera del dì di festa», "Alla luna», «La vita solitaria», "A Silvia», "Le ricordanze», "Canto notturno di un pastore errante dell'Asia», «La quiete dopo la tempesta», «Il sabato del Villaggio», «Il pensiero dominante», "Amore e morte», "A se stesso», "Aspasia», "Sopra un basso rilievo antico sepolcrale», "Il tramonto della luna», «La ginestra o il fiore del deserto», "Imitazione» y «Scherzo». Como broche de su antología, Sánchez Rosillo incluye un esbozo de poema que no forma parte de los Cantos, «Il canto della fanciulla», porque, "aun inconcluso, me ha parecido siempre maravilloso" (Sánchez Rosillo, 2004a: 197). En sus notas a la obra completa de Leopardi 
reúne poemas de las dos etapas mencionadas y desvela en sus notas tanto lo que le interesa como lo que le distancia de ellos, revelando de ese modo una poética propia. El escritor llega a afirmar que los poemas que dejó fuera "poco pueden decirle hoy al simple y buen lector de poesía. No son más que materia muerta, de esa que hace las delicias de eruditos y filólogos» (Sánchez Rosillo, 2004a: 13).Así pues, estamos ante una antología marcadamente personal. El poeta no llevó a cabo versiones de los Cantos, sino que trató de «ser fiel en todo momento al espíritu y a la letra» de los textos, evitando al mismo tiempo «un exceso de literalidad» (Sánchez Rosillo, 2004a: 14). Por otro lado, mantiene en su traducción la métrica de los poemas, pero descarta la rima, lo que no considera una pérdida sensible, dado que «bastantes poemas» de Leopardi no la tienen, y, en los que sí aparece, suele hacer «un uso muy moderado de la misma» (Sánchez Rosillo, 2004a: 15). De hecho, Sánchez Rosillo tiende a prescindir de la rima en sus poemas, en los que, por otro lado, son mayoritarios los versos endecasílabos y los heptasílabos, como en Leopardi.

Debido a que la poética de Sánchez Rosillo (2004a: 191) busca un lenguaje «natural» y evita «lastre retórico, frases largas, intrincados hipérbatos», no se identifica con el poema «La retama o la flor del desierto» («La ginestra o il fiore del deserto»). Si bien reconoce que surgen "espléndidos pasajes» a lo largo de su desarrollo, le parece «digresivo» y que "hay en sus versos un exceso de abstracta y seca filosofía en un inoportuno primer plano; el lenguaje es poco natural y pesa en él cierto lastre retórico». Asimismo, «las larguísimas frases, complicadas por intrincados hipérbatos, desdibujan un tanto la línea del poema».

Por el contrario, al igual que ocurre con buena parte de los Cantos que antologó, Sánchez Rosillo (2004a: 172) persigue «la meditación sobre el tiempo y la muerte a través del ejemplo concreto de su vida", y para lograrlo no confia en el intelectualismo sino en la creación de un poema "vívido, palpitante», señala en referencia a uno de los que prefiere, "Los recuerdos». De esta composición, Sánchez Rosillo ofrece una anotación que bien podría acompañar, mutatis mutandis, a muchos de sus poemas (si bien existe una diferencia evidente en cuanto a la extensión, ya que el poeta español rara vez excede el centenar de versos - en «La acacia» $\mathrm{y}$ «Casta diva»

(1956: 93 y 324, n. I), Sergio Solmi indica que este fragmento se suele considerar un paso inicial del canto "A Silvia». 
lo hace por muy poco, y en «Los pinares de Potsdam» se acerca a los 140-, mientras que el poema de Leopardi alcanza los 173 versos):

El lenguaje de «Los recuerdos» — como sucede siempre en la gran poesía - es extremadamente sencillo, desnudo y conciso; ni una sola palabra sobra en estos versos, a pesar de la considerable extensión del poema.

Resulta significativo que Sánchez Rosillo no solamente hable de preferencia por los poemas que se construyen con ese tipo de lenguaje, sino que lo considere necesario para la gran poesía. Al margen del posible carácter hiperbólico de la afirmación, es indudable que el escritor asume su poética con verdadero convencimiento. Citaré, a continuación, una de las estrofas de este poema, tan significativo en relación con la claridad de los versos del poeta italiano, que la poesía de Sánchez Rosillo comparte indudablemente:

Chi rimembrar vi può senza sospiri, O primo entrar di giovinezza, o giorni Vezzosi, inenarrabili, allor quando Al rapito mortal primieramente Sorridon le donzelle; a gara intorno Ogni cosa sorride; invidia tace, Non desta ancora ovver benigna; e quasi (Inusitata maraviglia!) il mondo La destra soccorrevole gli porge, Scusa gli errori suoi, festeggia il novo Suo venir nella vita, ed inchinando Mostra che per signor l'accolga e chiami? Fugaci giorni! a somigliar d'un lampo Son dileguati. E qual mortale ignaro Di sventura esser può, se a lui già scorsa Quella vaga stagion, se il suo buon tempo, se giovanezza, ahi giovanezza! è spenta?

(Leopardi, 2004: 54).
¿Quién recordaros puede sin suspiros, Oh despuntar de juventud, oh días Inenarrables, deliciosos, cuando Al absorto mortal por vez primera Sonríen las doncellas y a su lado Toda cosa sonríe; envidia calla, Aún no despierta o bien benigna; y casi —inusitada maravilla! — el mundo La diestra protectora le concede, Excusa sus errores, su llegada A la vida festeja y, doblegándose, Lo acepta por señor y así lo llama? ¡Fugaces días! Tal como el relámpago Desvaneciéronse. ¿Quién ignorante De desdicha será si ya ha vivido Esa hermosa estación, si su edad bella, Si juventud, ay, juventud apagose?

(Leopardi, 2004: 55)

Además de la claridad, ha de tenerse muy presente el autobiografismo del poema. "Los recuerdos" es un poema por completo autobiográfico (como autobiográficas son la mayoría de las páginas leopardianas que hoy más nos interesan)", asegura Sánchez Rosillo (2004a: 172), cuya poesía también se construye a partir de lo vivido y que descree de las separaciones rotundas entre el poeta y un supuesto sujeto poemático totalmente ficcional (Sánchez Rosillo, 2005: 31). En este sentido, Prieto de Paula (1989: 23), con motivo de la publicación de Autorretratos, afirmó que «todos los libros de 
poemas de Eloy Sánchez Rosillo [...] son retratos de interior -del interior del poeta-», y se refirió a ellos, además, como "confesiones personales, autobiografia apenas simulada». De igual modo, Leopoldo Sánchez Torre (1993: 13), al reseñar la primera edición de Las cosas como fueron (1992), que reúne Maneras de estar solo, Páginas de un diario, Elegías y Autorretratos, puso de relieve este carácter autobiográfico:

Los poemas de Sánchez Rosillo se van sucediendo como páginas de un diario que elaboran el autorretrato de un personaje que en esta poesía, como en la de Juan Ramón Jiménez, trata de identificarse al máximo con la persona real que está tras el poema (hasta el punto de que en dos poemas del último libro el interlocutor en que se desdobla el yo se llama Eloy).

El tono elegíaco del poema «La tarde» está presente en Sánchez Rosillo desde su primer libro, Maneras de estar solo (1978), a pesar de que lo publicó antes de cumplir los treinta años, con poemas escritos entre 1974 y 1977, mostrando una precoz conciencia de la fugacidad de la vida. Así, el escritor se convirtió pronto en el poeta elegíaco por excelencia de la generación de 1968. Puede afirmarse que esta característica, irremisiblemente unida al tópico del tempus fugit, forma parte del corazón mismo de su palabra poética -con los matices que se verán, relativos a la evolución de su idea del paso del tiempo-. Sirva, como muestra, «Todo lo que ha perdido», del mencionado libro Maneras de estar solo ${ }^{4}$ :

Hace ya tanto tiempo de todo aquello, que apenas si le es posible al hombre recuperar por un instante algún vestigio

del fulgor en que ardieron los años de la inocente plenitud: años que transcurrían lentamente en la inicial claridad de un mundo al que se abrían confiados sus ojos.

A veces puede ver a un niño solitario que mira cómo acuden los pájaros del atardecer a la arboleda en la que con frecuencia tienen lugar sus juegos.

Otras veces regresan las imágenes del adolescente

4 Salvo que se indique lo contrario, los versos de Sánchez Rosillo estarán tomados de Las cosas como fueron, en su edición de 2018, a excepción, lógicamente, de los poemas de su último libro, La rama verde (2020), del que sigo la primera edición. 
que, encerrado en su cuarto, toma un libro en las manos o escribe en un cuaderno arrebatadamente y se siente por esto distinto de los otros.

Pero todo es confuso.Y el hombre que hoy con emoción recuerda lo que no le fue dado retener, todo lo que ha perdido, sabe el dolor que cuesta volver a los lugares del pasado, y sabe que es inútil intentar revivir en el poema una sonrisa, un nombre, unas palabras dichas en una mañana lejanísima, en una tarde irrecobrable.

Esta composición lamenta que no puedan recuperarse tanto unos momentos vividos en la niñez como otros que tuvieron lugar en la adolescencia, cuando nace en el protagonista poemático la voluntad de escribir, y se siente por ello diferente a otros adolescentes. Estos recuerdos le provocan una emoción por el pasado irrecuperable, en este caso haciendo explícito su escepticismo hacia cualquier modo de aprehender los momentos felices mediante el regreso o a través de la creación poética.

Otro poema de particular relevancia en lo que atañe al dolor por el tiempo que se fue, porque une a Sánchez Rosillo y a Leopardi de singular manera, es el monólogo dramático «Recanati, agosto de 1829 (Homenaje a Leopardi)», de La vida, en el que Sánchez Rosillo pone en boca del poeta italiano un angustioso lamento por el tiempo que se ha ido y por el destino que ha tomado su vida, con un final implacable: «El recuerdo me depara / la extraña flor de la melancolía».

Junto con la claridad, el autobiografismo y el lamento por el paso del tiempo, que entrelazan las poéticas de ambos escritores, existen otros elementos concretos que cobran importancia en sus versos y que no pueden obviarse, como la naturaleza, los pájaros o la luna. Respecto a la naturaleza, que Sánchez Rosillo reconoce haber aprendido a mirar de manera directa en Leopardi (en López-Vega, 2016: 49), pueden mencionarse poemas como «La acacia» y «Lilas blancas en un jardín nocturno", de Páginas de un diario (1981), el primero vinculado a los tópicos de beatus ille y alabanza de aldea y el segundo al collige, virgo, rosas; «De las cosas del campo», de Elegías (1984), en el que el autor recuerda que de niño sabía «ser libre y ser feliz, estar de acuerdo / con la verdad sencilla y misteriosa / de la naturaleza»; o, por añadir algunos ejemplos de La rama verde (2020), 
su último libro publicado hasta la fecha, los poemas «Contrastes» y «Un huerto claro», en los que conviven la tragedia del vivir con el canto a la naturaleza. Sirva como ejemplo «Un huerto claro», en el que la voz poemática se refugia en un recuerdo de la infancia:

Da igual que sea enero y estés solo, que el viento silbe y haga tanto frío; poco importa también que llueva a cántaros.

Tú estás a salvo en tu memoria. Mira el huerto aquel de tu niñez. Es mayo y te ampara este sol risueño y joven que desciende del cielo y que se posa confiado, curioso, complacido, en los naranjos y los limoneros. $\mathrm{Y}$ en tu propia cabeza, que arde pura, llena de bendición. Trascurre frágil, en su cristal eterno, la mañana.

Tienes cinco o seis años a lo sumo.

Dentro de tu pequeño corazón, o entre las ramas de esos grandes pinos, oyes cantar un pájaro — ¿un jilguero?del que tú ignoras todavía el nombre.

Al final del poema aparece otro de los elementos mencionados, los pájaros, que están presentes a lo largo de toda la obra de Sánchez Rosillo. Recuérdese que el primero de los Cantos que antologa es precisamente "Un pájaro solitario» (Leopardi, 2004: 19-23), en el que Leopardi ve la semejanza entre sí mismo y un pájaro por su soledad y porque opta por no volar, evitar diversiones y pasar el tiempo más bello de su vida cantando (escribiendo), lo que tal vez le lleve a mirar atrás con desconsuelo llegada la vejez. Y en el quinto de los Cantos seleccionados por Sánchez Rosillo, «La vida solitaria», la primera estrofa evoca un optimismo del que participa «el murmullo / Primero de los pájaros» (Leopardi, 2004: 33), mientras que la soledad de la segunda estrofa se reafirma en un entorno en el que «No canta ni sus plumas bate el pájaro» (Leopardi, 2004: 35).

En Sánchez Rosillo, los pájaros formarán parte esencial tanto de la evocación de un pasado perdido («El Malecón», de Elegías; «Volver», de La vida; «Acerca del jilguero», de La certeza) como del entorno que se celebra, con un optimismo que sería impensable en la obra de Leopardi.Así, "Golondrinas en septiembre», de Sueño 
del origen (2011), en el cual, en una «[m]añana de oro limpio y bien pulido», el poeta ve volar las golondrinas «por la mañana de oro / y por la luz que hay dentro de mi pecho".

No menos importante resulta la presencia de la luna en las obras de ambos poetas. En los Cantos de Leopardi, el astro es objeto de contemplación («La noche del día de fiesta») y de entrañables interpelaciones ("A la luna», «La vida solitaria», "Canto nocturno de un pastor errante de Asia»). En la poesía de Sánchez Rosillo también es, por supuesto, contemplada («El naranjo de la plaza alegre», de Páginas de un diario; «Reincidencias», de Elegías).Y, en Autorretratos, la luna devuelve al protagonista poemático a su infancia («Nocturno del mar Menor»), lo acompaña en un viaje al futuro que le hace ser consciente de la perdurabilidad de los momentos de plenitud ( $U \mathrm{Ubi}$ sunt?») y hasta provoca en él una experiencia cercana a lo místico ("Casta diva»). Un poema relacionado con estos es «Luna llena», de Elegías, plegaria en la que el protagonista llama a la luna «madre» y pone «bajo tu dulce protección los cantos / que este libro reúne, y te suplico / que los acojas y que no les niegues / el don supremo de tu luz divina». Precisamente "Luna llena» y "Casta diva» han sido puestos como ejemplos de poemas en los que Sánchez Rosillo "consigue una seca intensidad solo comparable a la de Leopardi» (García Martín, 1996: 237).

\section{UNA EXÉGESIS INTEGRADORA}

La obra poética de Leopardi no podría entenderse sin su angustia y su profundo desengaño vital, relacionados con el complejo ambiente en el que creció y con sus padecimientos físicos (vid., por ejemplo, Solmi, 1956: XI-ss.; Solmi, 1966: XXXIX-XLIII; Navarro, 1994: XVII-XXVIII). Sergio Solmi (1956: XXIX) relaciona el desarraigo vital de Leopardi con «un approfondimento della concienza di esistere» que repercutirá en la significación de su obra:

Ed è la presenza di un tale approfondimento che, perseguito lungo le scoscese pareti del male, della negatività e della morte, dimostrò per pura via intuitiva la finale irreducibilità ad essi della vitalità e del sentimento, a conferire all'opera di Leopardi quel carattere di attualità che, mentre lo costituisce fra i grandi classici della poesia d'ogni tempo, fa della 
sua esperienza umana e poética una sorta di modello per la nostra operosa disperazione di moderni.

Por su parte, Diego Navarro (1994: XxviII) señala que Leopardi "fue un hombre profundamente infeliz» y «trató de demostrar a los hombres que sus aspiraciones y sus anhelos solo son ilusiones y vanas esperanzas».

Sánchez Rosillo, a pesar de que reconoce haber aprendido lecciones importantes como poeta gracias a Leopardi, y de que existen ecos del autor italiano que se perciben en su obra, asegura que no puede acompañarlo en el «radicalismo nihilista de algunos de sus poemas». Pero, al mismo tiempo, propone una lectura distinta de dicha tendencia de Leopardi:

En la cabeza del poeta, ciertamente, habitaba un filósofo nihilista - lo que sin duda es sumamente dañino para la poesía, que ha de ser siempre, de uno u otro modo, un canto de afirmación, una declaración de amor a la vida—; en su cuerpo, por otra parte, yacía desde el arranque mismo de la juventud un hombre muy enfermo y a punto de morir — circunstancia que puede también perjudicar la labor creadora-, pero, no obstante, en el espíritu del Leopardi mejor, como en el de todo poeta verdadero, alentaba un ser confiado que a pesar de sus negras ideas y de sus insufribles desdichas cantaba la hermosura del mundo y el privilegio de estar vivo (Sánchez Rosillo, 1999: 9).

Como muestra, el escritor cita el poema de Leopardi «El sábado en la aldea» («Il sabato del villaggio»), que le parece imposible que pudiera ser escrito por alguien «que no creyera en la vida ni se sintiera atraído por lo vivo" (Sánchez Rosillo, 1999: 9). Un ejemplo de ello es la descripción de la joven con la que se abre el poema:

La donzelletta vien dalla campagna,

In sul calar del sole,

Col suo fascio dell'erba; e reca in mano

Un mazzolin di rose e di viole,

Onde, siccome suole,

Ornare ella si appresta

Dimani, al di di festa, il petto e il crine.

(Leopardi, 2004: 76)
La jovencita vuelve de los campos,

Cuando el sol ya se oculta,

Con su haz de hierba, y en la mano trae

Un manojo de rosas y violetas

Con el que, como suele,

Mañana, día de fiesta,

Piensa adornarse el pecho y el cabello.

(Leopardi, 2004: 77). 
La cercanía de la fiesta reconforta y hace que este día de víspera sea el más grato, «Esperanzado, alegre», mientras que la jornada de la fiesta traerá "pena y tedio» y la cercanía de la vuelta al trabajo en la mente de cada uno. De ahí la exhortación final:

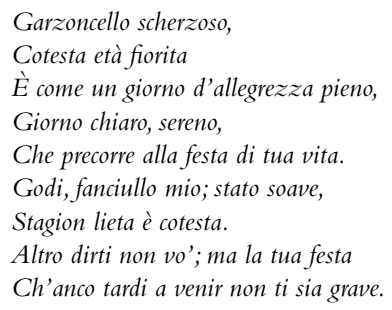

(Leopardi, 2004: 78).

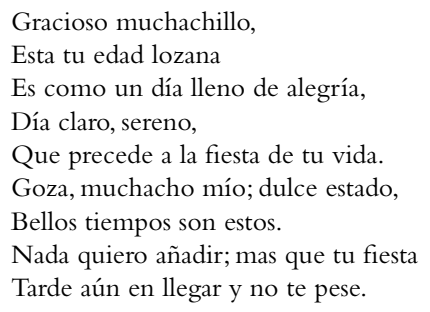

(Leopardi, 2004: 79).

Por otro lado, sin llegar al nihilismo, la poesía rosillana, sobre todo de sus primeros libros, da cabida ampliamente a la tragedia del vivir. Por ejemplo, pueden mencionarse poemas como «De la tristeza del regreso», «El jinete», «Dejadme aquí», «El viajero» $\mathrm{y}$ «Las sombras anteriores», de Maneras de estar solo; «La espera (Homenaje a Ramón Gaya)», «Canción», «Dice adiós a su juventud» y «Sonata para piano y violonchelo", de Páginas de un diario; o, para no mencionar solo ejemplos de sus primeros libros, «Melancolía» y «Envejecer», de La vida.

\section{UN CAMINO PROPIO}

La relación entre la obra poética de Eloy Sánchez Rosillo y la de Giacomo Leopardi resulta, como se ha visto, indudable. Sin embargo, como todo verdadero poeta, el autor español siguió un camino distinto, incluso en una cuestión tan central en su diálogo con Leopardi como es la reflexión sobre el paso del tiempo. Así, la distancia entre ambos comienza a percibirse en la primera etapa de Sánchez Rosillo, ya señalada, que abarca hasta 1996, porque, aun siendo mayormente elegíaca, da cabida a la celebración del pasado irrecuperable. Un ejemplo lo constituyen estos versos del poema «Volver a aquella plaza», de Maneras de estar solo:

Pero es posible regresar, volver mil veces

a los lugares del deseo, a los sitios que la pasión eligiera. 
Basta con que miremos hacia atrás, con que aprendamos que el tiempo pasa, pero permanece.

Y es que, para el escritor, las diferencias entre poesía elegíaca y poesía celebrativa «no son tan sustanciales como parece, y a menudo ambas modalidades poéticas pueden darse de manera entremezclada en un mismo poema» (Sánchez Rosillo, 2005: 32-33). El autor reflexiona así sobre este personal enfoque:

La poesía hímnica celebra la alegría de vivir y la hermosura del mundo en presente, mientras que la elegíaca efectúa similar celebración retardadamente, es decir, cuando lo que se pretende celebrar se encuentra ya concluido y en el pasado, en un más o menos remoto pretérito, y de ahí se deriva por cierto su lamento y su tono melancólico (Sánchez Rosillo, 2005: 33).

Araceli Iravedra (2016:358) se ha referido a un «verdadero punto de inflexión» en la obra de Sánchez Rosillo con la publicación del mencionado libro La certeza (2005), y ha sintetizado bien el cambio que se produce en su poesía:

Hasta entonces, la experiencia del mundo habitaba en la memoria; desde ahora, el registro melancólico y la conciencia de los límites aparecen mitigados por una nueva emoción de plenitud, un estadio en el que el yo ha conquistado la estoica conformidad con el presente, cediendo el testigo a la rendida celebración de existir.

El nuevo planteamiento hizo que cambiara el ámbito fundamental en el que se despliegan los momentos luminosos, que de ceñirse casi siempre a la memoria pasaron a ocurrir en el presente. Así, la distancia con Leopardi se ha hecho más evidente según ha ido imponiéndose en su obra lo celebrativo (sobre el cambio producido en esta segunda etapa, vid. Eire, 2005: 157-158; PozueloYvancos, 2007: 48-50; Prieto de Paula, 2007; Morante, 2014: 62-ss; Iravedra, 2016: 358). De esta forma, su poesía ha pasado a mostrar «la simultaneidad y la perennidad en la que todo se nos ofrece cuando dejamos de percibir el tiempo de manera lineal y fragmentada» (Sánchez Rosillo, 2018: 10).

A este respecto, resulta muy significativo el poema «En la mañana inmensa», de La rama verde, que, como apunta García Martín 
(2020), hace referencia a un poema de la etapa elegíaca de Sánchez Rosillo, «La playa», de Autorretratos - libro de 1989-, pero con un final en el que se observa claramente el cambio. En «La playa», la ilusión de estar con el hijo se hace «añicos» al escuchar «de pronto, / el ruido terrible y oscuro y velocísimo / que hace el tiempo al pasar», y el niño crece y se aleja, se hace un hombre, y ese día feliz no existió, y busca a su padre, que acaso ha muerto (para un análisis de este poema, vid. Díez de Revenga, 2007: 75-82). En cambio, en el poema "En la mañana inmensa», «el amor no transcurre: / ocurre. Su obstinado latir insiste oculto, / a salvo para siempre en nuestro pecho», y padre e hijo permanecen «desde el principio, / en el mar del verano, bajo el sol, / dentro de este diamante que fulgura, / de esta mañana inmensa que es la vida».

Por último, citaré el poema «Este día tan único», de Quién lo diría (2015), que se sustenta en la celebración del presente:

Qué raro ser yo hoy

el que escucha y distingue,

el que mira las cosas y las une,

quien está en el secreto

de este día tan único.

Oigo crecer la hierba, oigo rodar la tierra por el cielo.

¿Por qué yo?, me pregunto. Qué extrañeza.

No sé cómo ha ocurrido.

Caminaba deprisa. Me detuve

y comprendí.Y este saber me excede.

De este modo, en su segunda etapa, el yo lírico de los poemas de Sánchez Rosillo ve con más nitidez que la felicidad no está solo en el recuerdo del pasado, sino también en un presente que no ha de doler por su perdurabilidad, un presente del que hay que aprehender lo que tiene de inmortal, celebrándolo mientras se vive, sin esperar a la melancolía del recuerdo.

\section{CONCLUSIÓN}

La relación de Eloy Sánchez Rosillo con la poesía de Giacomo Leopardi puede comprenderse en profundidad gracias, en buena parte, a la antología que realizó de los Cantos, en la que no solo da 
su punto de vista sobre el magisterio que la obra de Leopardi ejerció sobre él, sino que además explica en valiosas notas con qué aspectos de su poesía se identifica y con cuáles no. Tanto dichas notas como otras fuentes mencionadas en este trabajo ponen de manifiesto la preferencia de Sánchez Rosillo por la claridad, la naturalidad y la precisión, el alejamiento del intelectualismo y la búsqueda de un poema "vívido, palpitante». Todo ello lo aprendió en los poemas de Leopardi, hasta el punto de que considera que el escritor italiano «me reveló el tono adecuado para la expresión de la intimidad verdadera». A estas cualidades hay que sumar el autobiografismo y el tono elegíaco, que también resultan esenciales en la poesía de ambos autores, o la presencia de elementos como la naturaleza, los pájaros o la luna (la frecuente contemplación de esta última en los poemas de ambos escritores y las entrañables interpelaciones al astro podrían ser objeto de un futuro estudio).

Sin embargo, la idea de que en el recuerdo se pueden unir melancolía y celebración diferenció pronto las obras de Sánchez Rosillo y de Leopardi, aunque el español supiera entrever un delicadísimo amor a la vida incluso en poemas de notoria desolación del poeta italiano, llevando a cabo una exégesis integradora. Pero no puede obviarse que el poeta español ha seguido un camino propio, que se ha afianzado con la mencionada celebración melancólica de sus poemas elegíacos, y que ha evolucionado hasta la centralidad de la celebración del presente. Sánchez Rosillo ha llegado a la conclusión de que la felicidad también se encuentra en aprehender lo que el presente tiene de inmortal, celebrándolo sin esperar a la melancolía del recuerdo. Este cambio se ha producido paulatinamente. La publicación de La certeza, en 2005, marca la transición, pero no parece que haya una frontera excesivamente rígida entre ambos periodos, una cuestión que podrá analizarse, asimismo, en un futuro trabajo.

Así pues, la singularidad de la poesía de Sánchez Rosillo frente a Leopardi radica, en buena parte, en sus dos personales formas de afrontar el tempus fugit. Cada una de ellas, a su modo, diferencia su poesía de la de Leopardi y enriquece su diálogo con ella. En los últimos libros de Sánchez Rosillo, lo celebrativo se ha desplegado con tal fuerza que ha hecho más profunda la diferencia entre ambas poéticas. 


\section{BIBLIOGRAFÍA}

Colinas, Antonio (2006). «Giacomo Leopardi: entre el sentir sublime y el razonar desesperado», en Giacomo Leopardi, Cantos. Pensamientos, traducción y prólogo de Antonio Colinas, Barcelona, Círculo de Lectores / Galaxia Gutenberg, pp. 7-20.

Díez de Revenga, Francisco Javier (1992). «La poesía elegíaca de Eloy Sánchez Rosillo», en Historia y crítica de la literatura española, coord. Francisco Rico. Vol. 9: Darío Villanueva y otros, Los nuevos nombres: 1975-1990, Barcelona, Crítica, pp. 191-193.

— (2007). «Tiempo y tiempos en la poesía de Eloy Sánchez Rosillo (“La playa")", en La poesía de Eloy Sánchez Rosillo: el ruido del tiempo, ed. Ricardo Escavy Zamora, Murcia, Universidad de Murcia, pp. 75-82.

EIre, Ana (2005). Conversaciones con poetas españoles contemporáneos, Sevilla, Renacimiento. García de la Concha,Víctor (1993). «Las cosas como fueron», Poesía en el Campus [«Eloy Sánchez Rosillo»], 23, pp. 8-9. [Publicado previamente en «ABC Cultural», ABC, 29 de enero de 1993, p. 8]. García Martín, José Luis (1992). La poesía figurativa. Crónica parcial de quince años de poesía española, Sevilla, Renacimiento.

- (1996). Treinta años de poesía española (1975-1995), Sevilla / Granada, Renacimiento / Comares.

— (2020). «Hebras de luz», El Comercio. 13 de noviembre: https:// www.elcomercio.es/culturas/libros/hebras-20201113000817ntvo.html [Último acceso: 6 de septiembre de 2021].

Iravedra, Araceli (2016). Hacia la democracia. La nueva poesía (1968-2000), Madrid,Visor. Ladrón de Guevara, Pedro Luis (2000). «Leopardi y Recanati como motivo poético en los poetas españoles», en Relaciones culturales entre Italia y España: Leopardi y España, eds. Ángel L. Prieto de Paula y Juan A. Ríos, Alicante, Biblioteca Virtual Miguel de Cervantes: http://www.cervantesvirtual.com/ nd/ark:/59851/bmcb56g7 [Último acceso: 16 de mayo de 2021].

— (ed.) (2005). Leopardi en los poetas españoles, Madrid, Huerga y Fierro.

Lanz, Juan José (2011). Nuevos novísimos poetas. En la estela del 68, Sevilla, Renacimiento. LeOpardi, Giacomo (1956). Opere. Tomo I, ed. Sergio Solmi, Milán / Nápoles, Riccardo Ricciardi Editore.

- (1966). Opere. Tomo II, eds. Sergio Solmi y Raffaella Solmi, Milán / Nápoles, Riccardo Ricciardi Editore. 
- (1994). Cantos, introducción, traducción y notas de Diego Navarro, Barcelona, RBA.

— (2004 [1998]). Antología poética, edición y traducción de Eloy

Sánchez Rosillo, 2. ${ }^{\text {e }}$ ed., revisada y corregida,Valencia, Pre-Textos.

- (2006). Cantos. Pensamientos, traducción y prólogo de Antonio

Colinas, Barcelona, Círculo de Lectores / Galaxia Gutenberg.

- (2014). Canti, introduzione e commento di Andrea Campana, Roma, Carocci.

LóPEZ-Vega, Martín (2016). «Eloy Sánchez Rosillo abierto al instante»

[Entrevista], Clarín. Revista de Nueva Literatura, 121, pp. 46-51.

Morante, José Luis (2014). «Introducción», en Eloy Sánchez Rosillo, Hilo de oro. (Antología poética, 1974-2011), ed. José Luis Morante, Madrid, Cátedra.

Navarro, Diego (1994). «Introducción», en Giacomo Leopardi, Cantos, introducción, traducción y notas de Diego Navarro, Barcelona, RBA, pp. XVII-XXXI.

Pozuelo Yvancos, José María (2007). «Figuraciones del yo», en La poesía de Eloy Sánchez Rosillo: el ruido del tiempo, ed. Ricardo Escavy

Zamora, Murcia, Universidad de Murcia, pp. 29-50.

Prieto de Paula, Ángel L. (1989). «Los Autorretratos de Eloy

Sánchez Rosillo», Ínsula, 516, diciembre, p. 23.

- (1996). Musa del 68. Claves de una generación poética, Madrid, Hiperión.

- (2007). «La elegía y la construcción del presente», en La poesía de Eloy Sánchez Rosillo: el ruido del tiempo, ed. Ricardo Escavy Zamora, Murcia, Universidad de Murcia, pp. 99-112.

Sánchez Rosillo, Eloy (1992). Las cosas como fueron, Granada, Comares.

- (1999). «Sobre mi vieja relación con la poesía de Leopardi», Nadie Parecía, 2, otoño, pp. 8-9.

— (2004a [1998]). «Introducción», en Giacomo Leopardi, Antología poética, edición y traducción de Eloy Sánchez Rosillo, 2. ${ }^{a}$ ed., revisada y corregida,Valencia, Pre-Textos.

_ (2004b). Las cosas como fueron. Poesía completa. 1974-2003, Barcelona, Tusquets.

— (2005). «Garabatos de poética», en Eloy Sánchez Rosillo. Poética

y Poesía, Madrid, Fundación Juan March, pp. 15-35.

— (2014). Hilo de oro (Antología poética, 1974-2011), ed. José Luis Morante, Madrid, Cátedra.

- (2018). Las cosas como fueron. Poesía completa. 1974-2017, Barcelona, Tusquets.

_- (2020). La rama verde, Barcelona, Tusquets. 
SÁnchez Torre, Leopoldo (1993). «Palabras que regresan, palabras para entonces», Poesía en el Campus [«Eloy Sánchez Rosillo»], 23, pp. 13-14.

Siles, Jaime (2001). Más allá de los signos, Madrid, Huerga y Fierro.

Solmi, Sergio (1956). «Introduzione», en Giacomo Leopardi, Opere. Tomo I, ed. Sergio Solmi, Milán / Nápoles, Riccardo Ricciardi Editore, pp. XI-XxxviII.

— (1966). «Introduzione», en Giacomo Leopardi, Opere. Tomo II, eds. Sergio Solmi y Raffaella Solmi, Milán / Nápoles, Riccardo Ricciardi Editore, pp. XI-XLIII. 